\title{
People's awareness on effects of open burning of household waste in Kinondoni Municipality, Dar-es-Salaam
}

\author{
Paul Israel (B.SC. EHS 3 - 2006/7)
}

\begin{abstract}
\section{INTRODUCTION}

Open burning is the burning of any matter in such a manner that its products are emitted directly into the ambient air without passing through an adequate stack, duct or chimney. The materials burnt include paper, trees, trash, brush, leaves, cans, leather, plastics, grass, and other debris where smoke and other emissions are released directly into the air the contents of which results into health and environmental effects such as bronchitis, emphysema, lung cancer, immune system repression, reproductive system disorders, birth defects and others.
\end{abstract}

\section{OBJECTIVE}

To assess people's knowledge on the health and environmental effects associated with open burning of household wastes at Kinondoni Municipality in Dar es Salaam City.

\section{MATERIALS AND METHODS}

This was a cross sectional descriptive study that involved 300 respondents. Structured closed and open ended questionnaire were used in data collection and the study was carried in between February to May, 2007. Data coding was done during data collection \& quantitative data analysis was done through SPSS Version 12, a computer package programme, whereas qualitative data sociological/anthropological methods in data analysis were used.

\begin{abstract}
RESULTS
Health and environmental awareness of people on effects of open burning practice was high (61.7\%). However, out of 300 respondents, 213(71.0\%) reported to continue using open burning as their final disposal mechanism due to poor existing infrastructure (76.0\%), cost implication (94.8\%). Low frequency of waste collection (94.3\%) and as normal practice habit (46\%).
\end{abstract}

\section{CONCLUSION}

The results from this study showed that people are aware of the health and environmental effects associated with open burning of household wastes. However the existing infrastructure, low frequency of waste collection and refuse collection fee becomes the major barrier hence need thorough considerations

\section{INTRODUCTION}

Open burning is the burning of any matter in such a manner that products of combustion resulting from the burning are emitted directly into the ambient (surrounding outside) air without passing through an adequate stack, duct or chimney. Materials that can be burnt may be grouped into organic waste and inorganic waste, plus synthetic substances. Open burning also includes incineration devices that do not control the combustion air to maintain an adequate temperature and do not provide sufficient residence time for complete combustion ${ }^{4,8}$. Open burning has been practiced for long time in different communities in the world since the age of ancestors, it was simple and cheap to remove the waste from the environment within a short time at minimum energy and less utilizable resources, bringing about good, habitable, aesthetically pleasing environment. The ashes (by product of burning) were used as fertilizer in farms. Nowadays as there is advancement of technology, high population growth, rapid urbanization accompanied with rural - urban migration, most of the cities in the world have a lot of sources of waste which are becoming difficult to dispose. This includes domestic, institution, industrial, commercial, agricultural waste among others. Most of the wastes generated are not disposed of in a scientific manner hence leading to heaps of waste in various places in urban setting. Therefore the easiest method of disposal is burning either in barrel, backyard or in any suitable place within ones residence. Emissions from open burning of residential solid wastes are released at ground level resulting in decreased dilution by dispersion. Further it 
pollutes the air and poses a fire hazard. Pollutants vary depending on the type of garbage burned, but typically emissions include dioxins, ash, furans, halogenated hydrocarbons, carbon monoxide, lead, barium, chromium, cadmium, carbon dioxide, sulphur dioxide, arsenic or mercury ${ }^{11}$. The air pollution created by open burning has multisystemic involvements plus birth defects, cancer (especially dioxin) and are a danger to those with respiratory problems. Besides the above effects, other effects are related to global warming ${ }^{2}$.Countries such as USA, U.K and other developed ones are examples of those where laws regarding open burning have been enacted ${ }^{4}$. Although open burning is an unnoticed kind of practice, it poses major health and environmental impacts especially in high density and low-income areas with low free air circulation. This study therefore was assessing people's knowledge on health and environmental effects associated with open burning of household waste in an urban setting.

\section{METHODOLOGY}

A cross sectional descriptive study that involved 300 respondents was conducted at Mabibo ward in Kinondoni district Dar-es-Salaam between February and May, 2007. In order to get the required study sample, a multistage sampling technique was used.
One division out of four was randomly selected. The wards within the selected division were listed and one ward i.e Mabibo ward was randomly selected from the list. 300 households were randomly selected from different cells/hamlets where the respondents were obtained basing on willingness to participate. Structured Kiswahili Questionnaires were used to collect data from various respondents and additional observational information was documented. Data coding was done during data collection \& quantitative data analysis was done through SPSS Version 12, a computer package programme, whereas qualitative data sociological/anthropological methods in data analysis were used.

\section{RESULTS}

\section{Characteristics of Respondents:}

The study involved 300 respondents whose aged ranges between 19 years to 62 years $(S D=1.061)$. Majority of the respondents were from the age group of $35-54(35.7 \%), 55$ years and above had the least members (6.3\%). (See table 1).

More than 53\% (160) of respondents were male. The majority of the study sample had primary education (58.0\%), secondary education (33.7\%) and very few had higher education (8.3\%) (see table 1 below):

Table 1: Demographic data of the study sample $n=300$

\begin{tabular}{|l|l|l|l|}
\hline Demography & \multicolumn{2}{|l|}{ Sex of respondent } & \multirow{2}{*}{ No. of respondents } \\
\cline { 1 - 3 } a) Age group & Male & Female & \\
\hline $15-24$ & $21(61.8)$ & $13(38.2 \%)$ & $34(100 \%)$ \\
$25-34$ & $46(51.7)$ & $43(48.3 \%)$ & $89(100 \%)$ \\
$35-44$ & $54(50.5)$ & $53(49.5 \%)$ & $107(100 \%)$ \\
$45-54$ & $29(56.9)$ & $229(43.1 \%)$ & $51(100 \%)$ \\
$55+$ & $10(52.6)$ & $9(47.4 \%)$ & $19(100 \%)$ \\
Total & $\mathbf{1 6 0 ( 5 3 . 3 \% )}$ & $\mathbf{1 4 0 ( 4 6 . 7 \% )}$ & $\mathbf{3 0 0 ( 1 0 0 \% )}$ \\
\hline b) Level of education & & & \\
\cline { 1 - 2 } Primary education & $95(59.4 \%)$ & $79(58.0 \%)$ & $174(100 \%)$ \\
Form four - six & $46(28.8 \%)$ & $55(39.3 \%)$ & $101(100 \%)$ \\
Higher education & $19(11.9 \%)$ & $6(4.3 \%)$ & $25(100 \%)$ \\
Total & $\mathbf{1 6 0 ( 5 3 . 3 \% )}$ & $\mathbf{1 4 0}(\mathbf{4 6 . 7 \% )})$ & $\mathbf{3 0 0}(100 \%)$ \\
\hline
\end{tabular}

Figure 1: Waste disposal mechanisms -past experience $\mathbf{n}=\mathbf{3 0 0}$

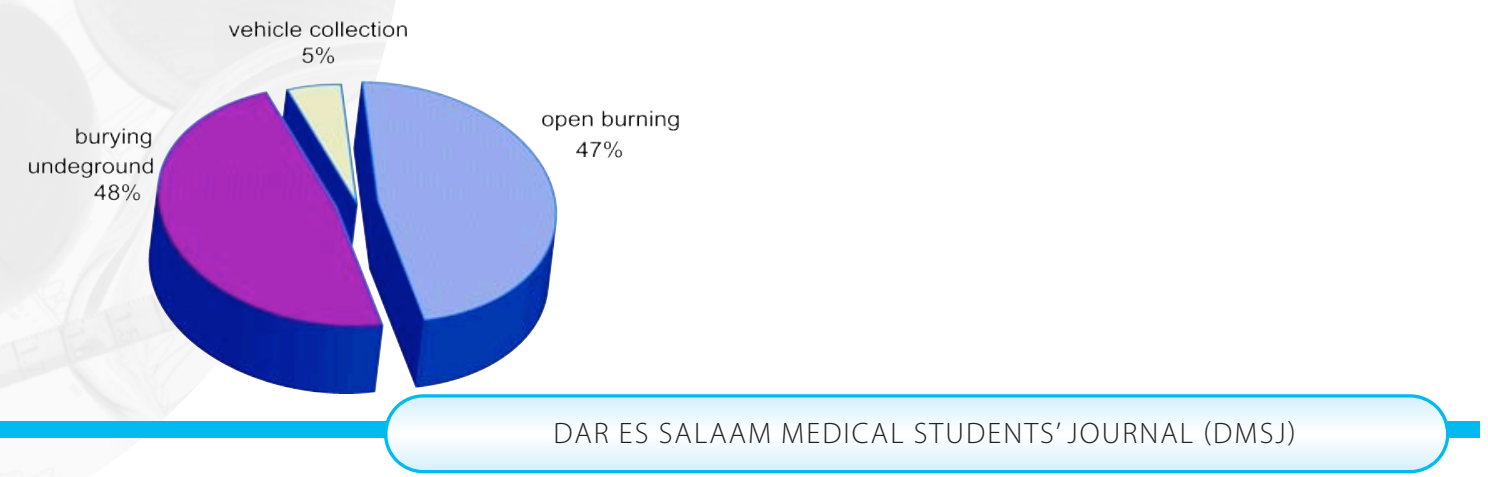


The analysis on the past experiences on disposal mechanism of solid waste as reported by all respondents; revealed that $48.0 \%$ buried waste underground, $47 \%$ was open burnt and $5 \%$ solid waste were collected by a vehicle collected. These findings give picture of how the disposal mechanisms commonly being practised by the community in the past few decades.

The study explored the current practices of solid waste disposal. The analysis revealed that 213(71.0\%) practiced open burning of household waste. Open burning took place along the street roads $(45.1 \%)$, in front of house (27.7\%), at the back yard (18.3\%) and the rest in the barrel (8.9\%).

This study was also aimed at knowing the type of solid waste often being burnt (multiple response were allowed). The result showed that, solid waste often burnt in households included tree leaves (72\%), plastics including bags and bottles (70.4\%), papers (68.5\%), Garbage i.e. food waste (65.3\%), tires (51.6\%), old mattresses (39.0\%) plus leather with worn out clothes (31.9\%). Most of these wastes were generated from different activities conducted around households.

Regarding final disposal mechanism, the result showed that, $71 \%$ of the household practises open burning as the final disposal of solid waste.

The study also investigated on the socio - economic factors that influenced open burning. The analysis of the findings revealed that, the practice appeared to be mostly conducted in slums and squatter area with people of low socio- economic status and highly populated lived. For example out of 213 respondents, $76.0 \%$ reported that the existing infrastructure of the area is a promoting agent towards this practice. It included roads among others that make an area not easily accessible to municipal vehicles to collect the waste and the houses are highly congested. Additional costs (94.8\%) involved for paying for the waste (refuse collection fee) was another factor that make people opt for open burning.

Further more $94.3 \%$ of the respondents reported that inefficiency solid waste collection system i.e low frequency of solid waste collection was another strong fact, whereas $46 \%$ of respondents reported that it was contributed to habit to some individuals.

Besides the above findings, the study assessed the awareness of the people on health and environmental effects associated with open burning. The findings showed that $61.7 \%$ were aware of the health and environmental effects on open burning of households waste.
However among those who reported to have known the health effects of open burning (multiple response), $91.4 \%$ responses reported the reduction in visibility. $89.2 \%$ eye irritation, $81.1 \%$ water pollution, $72.4 \%$ fire outbreaks to the nearby facility, $33.5 \%$ undesirable smell, 33.5\% cancer, $22.7 \%$ difficult in breathing. 15.1\% immune system repression and $9.2 \%$ reproductive disorders.

\section{DISCUSSIONS}

The analysis of the findings has revealed that open burning practice is still a major approach used by residents of the city as their final disposal mechanism (71\%). This may be traced from the past decades where the major disposal mechanisms were underground burial of waste and open burning. By that time there was enough space and the land had natural assimilation capacity to the amount and type of waste generated at that time.

The study also has revealed that residents did practice open burning in barrels, in the backyard, in front of the house and along the street roads. This shows that there isn't enough space for carrying out this practice as it was in the past. It may be due to rapid population growth accompanied with rural - urban migration that has resulted into congestion and unplanned settlements making an area in accessible.

Moreover synthetic substances such as plastics, leather, rubber and other materials such as tree leaves, old mattresses, garbage, cans, and trash were among those materials that were included in open burning. This has tremendously changed the nature and composition of wastes produced and the emissions results into air and environmental effects. Same compositions were reported in the study conducted in USA ${ }^{8}$.

However the majority of respondents were generally aware of the health and environmental effects associated with open burning, though the analysis showed that most of them knew the immediate causes and the long term causes were little known. This shows that more efforts are needed to educate the community on the long term effects associated with open burning.

Besides the above, infrastructure such as roads were reported as a major stumbling block towards proper waste collection to the temporally storage places established in different places within hamlets. This together with the socio-economic aspects of the community members posed a threat to many households as they are unable to sustain the refuse collection fee and this necessitates their decision of 
disposing the waste by open burning which they consider to be cheap with less time consumption.

Despite of the continuity of the practice in these areas, most people perceived it as a health and environmental problem. For example, out of 300 respondents, 238 (79.3\%) reported that it is a bad practice in the community. This was also observed in USA and UK where it led to an establishment of open burning regulations in those countries as the result; the practice was later banned and highly restricted ${ }^{4}$.

Furthermore the extent to which people are aware of the magnitude and fate of the problem may be another challenge that may need accurate educational need assessment to clearly define the gap between what is known and what should be the action to both local government and the people to improve the practice.

Different options were given on the removal of solid waste at household level. These included collection of solid waste to collection point where the waste were transported to the dump site, burying waste underground if the space allows, paying for local waste collectors whose costs were low. However due to costs, the nature of the area, and the existing infrastructure, these options might not well be implemented. The community has to be sensitized on the importance of waste removal in their area by collecting them to the nearby collection point.

\section{CONCLUSSION}

The results from this study showed that people were aware of the health and environmental effects associated with open burning of household wastes. However the existing infrastructure, low frequency of waste collection and refuse collection fee becomes the major stumbling block hence need thorough considerations.

\section{RECOMMENDATIONS}

There is a need to carry out comprehensive studies that will involve air, water and soil sampling to look on the effects of the practice in the environment. The contents of the emissions should be determined. Community based interventions should be used to incorporate and involve people in discouraging this practice. Various waste disposal mechanisms including recycling should be designed to suit for the existing infrastructure of different areas. Health education on waste management is needed focusing on waste sorting at the source in order to separate different types of waste so that different types of wastes should be treated separately.

\section{ACKNOWLEDGEMENT}

I would like to thank my supervisor Dr. E.J. Kayombo from the Institute of Traditional Medicine (MUCHS) for his tireless help in conducting my study, the administration of Kinondoni Municipality for allowing this task to be accomplished.Also I appreciate the HESLB for sponsoring this work plus my course mates who helped me in data collection, advice and favourable environment during my study.

\section{REFERENCES}

1. Burningman, (2005): Preparation: environmental and health effects of burning on the playa, USA.

2. Christopher Neural, (2003): Work on Waste: Open burning of Domestic wastes: The single largest source of Dioxin to air, 82 Judson st, Canton. USA.

3. Chaggu EJ, Kaseva ME, Kassenga GR, Mbuligwe SE, (1998): Research and Pilot Scale Demonstration Project on Compositing of domestic solid waste: Case study- Sinza Dar es Salaam. Department of Environmental Engineering. University College of Lands and Architectural studies (UCLAS).

4. Environmental Protection Agency (EPA), (1997): Evaluation of emission from the open burning of Household waste in Barrel, Technical Report, Vol 1\&2.USA.

5. Environmental Protection Commission (EPC), (2005): Health and Environmental effects of Open burning -Hillsburgh.

6. FRTR, Remediation Technologies Screening Matrix and Reference Guide, Version 4,

7. Global Day of Action Against Waste and Incineration, (2005): Tanzania, Madhara ya uchomaji moto taka kwa afya na mazingira, Taarifa Kwa Vyombo Vya Habari, th Septemba 2005.

8. Jenipher MG, Steven. E C, 2003: The Michigan Open Burning Guide, Regulations and Alternatives. USA.

9. Mbuligwe SE, Kassenga GR, Kaseva ME, Chaggu EJ, (2002): Potential constraints of Compositing domestic solid waste in developing countries: findings from pilot study in Dar es Salaam, Tanzania; Department of Environmental Engineering, University College of Lands and Architectural Studies (UCLAS).

10. Paul M. Lemieux Christopher C. Lutes Dawn A. Santoian, (2003): Emissions of organic air toxics from open burning: a comprehensive review

11. Wisconcin Department of Natural resources. (WDNR). 